\title{
Práticas de governança corporativa adotadas e divulgadas pelos fundos de
} pensão brasileiros

\author{
Practices of corporate governance adopted and disclosed by brazilian pension funds \\ Prácticas de gobierno corporativo adoptadas y divulgadas por fondos de pensiones \\ brasileñ̃s
}

\section{Leticia Cesar de Lima}

Mestre em Administração e Controladoria pela Universidade Federal do Ceará Endereço: Av. da Universidade, n 2431, Bairro Benfica

CEP: 60020-180 - Fortaleza/CE - Brasil

E-mail: 1eticiacesar04@gmail.com

Telefone: +55 (85) 3366-7816

\section{Marcelle Colares Oliveira}

Doutora em Ciências Contábeis pela Universidade de São Paulo

Professora do Programa de Pós-Graduação em Administração e Controladoria da

Universidade Federal do Ceará - UFC

Endereço: Av. da Universidade, n 2431, Bairro Benfica

CEP: 60020-180 - Fortaleza/CE - Brasil

E-mail: marcellecolares@uol.com.br

Telefone: + 55 (85) 3366-7816

\section{Vera Maria Rodrigues Ponte}

Doutora em Ciências Contábeis pela Universidade de São Paulo

Professora do Programa de Pós-Graduação em Administração e Controladoria da

Universidade Federal do Ceará - UFC

Endereço: Av. da Universidade, n 2431, Bairro Benfica

CEP: 60020-180 - Fortaleza/CE - Brasil

E-mail:vponte@fortalnet.com.br,

Telefone: + 55 (85) 3366-7816

\section{Sílvia Maria Dias Pedro Rebouças}

Doutora em Estatística e Inv. Operacional pela Universidade de Lisboa

Professora do Programa de Pós-Graduação em Administração e Controladoria da

Universidade Federal do Ceará - UFC

Endereço: Av. da Universidade, n 2431, Bairro Benfica

CEP: 60020-180 - Fortaleza/CE - Brasil

E-mail: smdpedro@gmail.com,

Telefone: +55 (85) 3366-7816

Artigo recebido em 09/11/2015. Revisado por pares em 20/11/2015. Reformulado em 17/12/2015. Recomendado para publicação em 28/12/2015 por Sandra Rolim Ensslin (Editora Científica). Publicado em 30/03/2016. 
Resumo

O objetivo do estudo é analisar as práticas de governança corporativa adotadas e divulgadas pelos fundos de pensão brasileiros e prováveis explicações à luz da Teoria Institucional. A pesquisa é de natureza quantitativa e descritiva. Foi estudada uma amostra de 140 entidades e utilizada a técnica da análise de conteúdo na análise de documentos, colhidos nos websites dessas entidades. A análise dos dados incluiu estatística descritiva, correlação de Spearman e teste $\mathrm{t}$ para amostras independentes. Observou-se que os fundos de pensão brasileiros tendem a adotar e divulgar predominantemente as práticas de governança legalmente impostas, explicando o isomorfismo coercitivo. Observou-se ainda que a idade, o tamanho dos fundos em termos de ativo e o tipo de patrocínio são variáveis que estão correlacionadas com práticas voluntárias, representando isomorfismo mimético. Concluiu-se, segundo a Teoria Institucional, que as práticas principalmente adotadas e divulgadas pelos fundos brasileiros decorrem de pressões coercitivas e culturais explicadas pelos isomorfismos identificados.

Palavras-chave: Fundos de pensão. Governança corporativa. Divulgação.

\begin{abstract}
The objective of the study is to analyze the corporate governance practices adopted and disclosed by the Brazilian pension funds and probable explanations in the light of Institutional Theory. The research is quantitative and descriptive. A sample of 140 entities was studied and used the content analysis technique in the analysis of documents collected in the Web portals of these entities. Data analysis included descriptive statistics, Spearman correlation and t test for independent samples. It was observed that Brazilian pension funds tend to adopt and disseminate predominantly legally imposed governance practices, explaining the coercive isomorphism. It was observed also that age, the size of the funds in terms of assets and the type of sponsorship are variables that are correlated with volunteer activities, explaining the mimetic isomorphism. It was concluded according to institutional theory that practices mainly adopted and disclosed by the Brazilian funds stem from coercive and cultural pressures explained by identified isomorphisms.
\end{abstract}

Keywords: Pension funds. Corporate governance. Disclosure.

\title{
Resumen
}

El objetivo del estudio es analizar las prácticas de gobierno corporativo adoptadas y divulgadas por fondos de pensiones brasileños y explicaciones probables a la luz de la teoría institucional. La investigación es cuantitativa y descriptiva. Se estudió una muestra de 140 entidades, con la técnica de análisis de contenido en el análisis de documentos recogidos en websites de estas entidades. El análisis de datos incluyó estadística descriptiva, la correlación de Spearman y lo test t para muestras independientes. Se vio que los fondos de pensiones brasileños tienden a adoptar y difundir las prácticas de gobierno legalmente impuestas, que explican el isomorfismo coercitivo. También la edad, el tamaño de activos de los fondos y el patrocinio son variables que se correlacionan con las prácticas voluntarias, que explican el isomorfismo mimético. Se concluyó de acuerdo a la teoría institucional que las prácticas adoptadas y divulgadas principalmente por los fondos brasileños provienen de las presiones coercitivas y culturales explicadas por isomorfismos identificados.

Palabras clave: Fondos de pensiones. Gobierno corporativo. Divulgación.

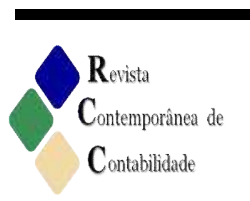




\section{Introdução}

Os fundos de pensão são entidades que investem altos valores em nome de terceiros, tais como: beneficiários, clientes e entidades relacionadas. Especula-se que os recursos dos fundos de pensão sejam capazes de financiar o desenvolvimento do País pela geração de recursos de longo prazo, sendo vistos também como cooperadores na formação da poupança interna (SANTOS; ANTUNES JUNIOR; LEIS, 2008). A relevância dos fundos para a sociedade e para a economia brasileira é elevada, observando-se aspectos como o percentual expressivo do patrimônio dessas entidades sobre o Produto Interno Bruto - PIB, conforme o Ministério de Previdência Social (MPS, 2011), que, em junho de 2013, correspondia a aproximadamente 14,7\% do PIB, segundo a Associação Brasileira das Entidades Fechadas de Previdência Complementar (ABRAPP, 2013).

Em comparação com as organizações em geral, os fundos de pensão possuem peculiaridades em sua estrutura e governo. Por exemplo, classificam-se conforme os planos de benefícios que administram, sendo denominados de plano comum, quando é acessível a um grupo restrito de participantes, como integrantes de uma única entidade; ou de multiplano, se disponíveis a grupos de participantes diversos. Os fundos também podem ser distinguidos segundo seus patrocinadores ou instituidores, categorizando-se em singulares, com apenas um patrocinador; ou multipatrocinadas, com mais de um (MPS, 2013). Particularidades como essas diferenciam os fundos de pensão, tornando-os um grupo específico de organizações a ser estudado em suas ações e práticas.

A Teoria Institucional oferece múltiplas percepções relativas ao exame das pressões institucionais em contextos diversos e das consequentes atitudes organizacionais, as quais tendem a assemelhar-se no caso de entidades expostas a conjunturas similares, remetendo-se ao isomorfismo institucional (DIMAGGIO; POWELL, 1983). Tolbert e Zucker (1996) incentivam o estudo da Teoria Institucional em cenários diversificados, a fim de promover comparações.

Dimaggio e Powell (1983) esclarecem que, ao longo do tempo, as organizações apresentam diversas semelhanças entre si, as quais advêm do processo de isomorfismo institucional, que pode ser coercitivo, oriundo de pressões externas formais ou informais; mimético, quando as organizações tomam outras como modelo, devido à incerteza; ou normativo, por pressões sociais ou profissionais.

Os motivos que induzem ao isomorfismo podem alterar-se de acordo com a organização; como exemplo, tem-se a busca por vantagem competitiva e legitimidade social. Essa procura por legitimidade pode resultar na adoção de práticas de governança. Ressalta-se, contudo, que, sendo apenas esse o intuito da organização, esta pode adotar ações superficiais que não refletem, de fato, em melhorias nas práticas de governança (SUDARSANAM; BROADHURST, 2012).

Souto e Musalem (2012) ressaltam que uma boa estrutura de governança para fundos de pensões pode funcionar como um impedimento para a utilização abusiva dos ativos do fundo. Lopes et al. (2010) reforçam que, por administrarem recursos financeiros de terceiros, os fundos de pensão devem suscitar confiança, a qual pode ser viabilizada pela divulgação de boas práticas de governança corporativa.

A governança vem sendo observada por profissionais e acadêmicos em diversos contextos organizacionais (KLAPPER; LOVE, 2004; LOPES et al., 2010; DUARTE, 2011; CARNEIRO; MAPURUNGA; PONTE; MORAIS, 2013; JARDIM, 2013; PICCOLI;

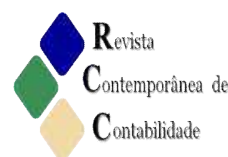


SOUZA; SILVA, 2014; SONZA; KLOECKNER, 2014; MENDES; FREIRE, 2014), inclusive concernente aos fundos de pensão, os quais têm recebido atenção como influenciadores das práticas de governança das companhias onde investem seus recursos (HEBB, 2006; PUNSUVO; KAYO; BARROS, 2007; JIAO; YE, 2013). Todavia, os fundos de pensão, como investidores institucionais, requerem mais atenção quanto à própria governança (CLAESSENS; YURTOGLU, 2013).

Diante do questionamento de por que os países, empresas e mercados não adotam boas práticas de governança voluntariamente, Claessens e Yurtoglu (2013) descobriram que aqueles estão dispostos apenas a algumas adaptações para não incorrerem em custos. Reis (2010) também afirma que a adoção das melhores práticas de governança corporativa está atrelada a uma questão crítica: os custos financeiros necessários para suportá-las.

No Brasil, a Resolução n. 13/2004, do Conselho de Gestão da Previdência Complementar (CGPC), objetivou estabelecer princípios, regras e práticas de governança, gestão e controles internos para os fundos de pensão, entretanto contempla pouco detalhamento sobre as ações de governança, deixando lacunas para seu cumprimento. A Resolução CGPC n. 23/2006, por sua vez, está relacionada à divulgação de informações, contribuindo para alguns aspectos concernentes às práticas de governança, todavia ainda incipientes.

Examinando tais lacunas regulativas, bem como a importância da governança corporativa nos fundos de pensão, devido a ser um fator determinante no desempenho dos investimentos, a consequente segurança de seus beneficiados e a expressividade sobre o PIB, este trabalho busca responder à seguinte questão de pesquisa: Quais as práticas de governança corporativa adotadas e divulgadas pelos fundos de pensão brasileiros e prováveis explicações à luz da Teoria Institucional?

O trabalho tem como objetivo geral analisar as práticas de governança corporativa adotadas e divulgadas pelos fundos de pensão brasileiros e prováveis explicações à luz da Teoria Institucional. Para sua consecução foram estabelecidos os seguintes objetivos específicos: (1) apresentar, de forma geral, aspectos da Teoria Institucional e do isomorfismo, da governança corporativa e da divulgação de informações relacionados a fundos de pensão; (2) verificar a existência de isomorfismo nas práticas de governança adotadas e divulgadas pelos fundos de uma amostra de fundos de pensão brasileiros; e, (3) examinar a associação entre as práticas de governança adotadas e divulgadas pelos fundos de pensão e a identidade dos patrocínios predominantes (particular, público, instituidor), a idade e o tamanho dos fundos (em termo de ativos e número de participantes).

A elaboração desta pesquisa surgiu da carência observada quanto a estudos sobre a governança nos fundos de pensão, inclusive no Brasil. Evans, Orszag e Piggott (2008) afirmam que, em comparação com a ampla literatura sobre governança corporativa, a literatura acadêmica concernente à governança dos fundos de pensão é muito limitada.

A adoção de elevados padrões de governança, por parte dos fundos de pensão, faz-se necessária ao considerar-se o amplo volume de recursos movimentado por estes, referente a milhões de trabalhadores. A importância da boa governança nos fundos de pensão reflete na melhoria do desempenho dos investimentos e na segurança de seu benefício. Entretanto, poucos estudos analisaram a divulgação de práticas de governança corporativa por fundos de pensão, em especial no Brasil, e buscaram explicações para os achados à luz da Teoria Institucional, sendo essa a proposta do trabalho.

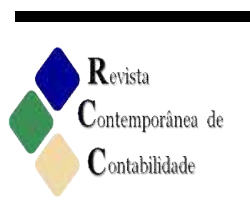


Portanto, o estudo pretende contribuir para o preenchimento da lacuna existente de estudos sobre governança corporativa nos fundos de pensão brasileiros. Ademais, a presente pesquisa constitui-se num mecanismo de incentivo na busca pela ampliação de estudos nessa área, a fim de promover a expansão desse conhecimento e viabilizar o aprimoramento da governança nos fundos de pensão e, por conseguinte, o desempenho destes. O estudo possibilita ainda que os gestores reflitam mais sobre a execução de suas atividades, mantendo a atenção de todas as partes interessadas.

\section{Referencial Teórico}

\subsection{Teoria Institucional e Isomorfismo}

$\mathrm{O}$ isomorfismo institucional tem sido aplicado em diversas pesquisas com o intuito de compreender as ações e os comportamentos organizacionais, uma vez que passaram a refletir procedimentos semelhantes no decorrer dos anos. Carvalho, Vieira e Goulart (2005) declaram que a abordagem institucional vem encontrando unanimidade nos estudos sociológicos e pertinentes às tendências teóricas mais recentes como promitente na explicação da sociedade organizacional.

De fato, observa-se que a Teoria Institucional se intensificou, quanto aos estudos organizacionais, em várias pesquisas no cenário brasileiro (ROSSONI; MACHADO-DASILVA, 2010; OLIVEIRA et al., 2012; RODRIGUES NETO; FREITAS, 2012). Tal fato remete às diversas possibilidades que essa teoria fornece quanto às pressões institucionais do ambiente exercidas sobre as organizações, principalmente, considerando a legitimação e a competitividade.

Essas pressões institucionais podem resultar em práticas isomórficas, ou isomorfismo, que, na visão de Dimaggio e Powell (1983), compreendem três perspectivas: (1) isomorfismo coercitivo, oriundo de pressões externas; (2) isomorfismo mimético, que reflete respostas para incertezas do meio onde a entidade está inserida, a qual passa a reproduzir ações de outras bem gerenciadas em busca de legitimidade; e, (3) isomorfismo normativo, decorrente de normas do âmbito social e do profissional.

Nesse entendimento, as pressões que geram o isomorfismo coercitivo podem ser formais ou informais e são exercidas de umas organizações para outras que dependem daquelas, bem como por expectativas culturais da sociedade onde as entidades atuam. Carvalho, Vieira e Goulart (2005) esclarecem que o isomorfismo coercitivo se refere a regulamentações, equivalentes a uma base legal, e as organizações se legitimam pela conformidade com as leis estabelecidas para sua esfera de atuação; dessa forma, refere-se principalmente a pressões relacionadas ao Estado.

No caso do isomorfismo mimético, as organizações tomam outra como modelo, devido à incerteza, portanto reproduzem procedimentos de outras entidades aparentemente mais bem-sucedidas, expostas a condições semelhantes, a fim de obter reconhecimento. $\mathrm{O}$ comportamento mimético expõe vantagens no sentido de economizar ações humanas. As organizações modelo podem estar cientes ou não dessa imitação. Tais modelos organizacionais podem ser repassados indiretamente, como por meio da rotatividade de funcionários (DIMAGGIO; POWELL, 1983). 
Dimaggio e Powell (1983) destacam ainda que as entidades mais antigas são tidas como modelo pelas novas e que as organizações vistas como mais legítimas ou bem-sucedidas são tidas por modelo para outras do seu ramo de atuação.

As pressões miméticas, sob a ótica de Scott (2008), compreendem elementos culturais cognitivos, que enfatizam concepções compartilhadas configurando a realidade social, ou seja, apoiadas pela cultura.

Segundo Carvalho, Vieira e Goulart (2005), os aspectos normativos da Teoria Institucional refletem fundamentalmente a moral, sendo a legitimidade de uma organização baseada em sua adesão a normas estabelecidas como padrões de comportamento. Essas normas originam-se dos mecanismos de controle e das profissões. Sudarsanam e Broadhurst (2012) reforçam essa ideia explanando que modificações, na conjuntura organizacional, originam pressões normativas, as quais não têm poder coercitivo, mas derivam da convergência por meio da socialização.

Assim, por exemplo, pressões normativas são oriundas da profissionalização, a qual é entendida como a junção de forças de membros de uma determinada profissão com o intuito de estabelecer condições e mecanismos de trabalho, deliberando sobre os parâmetros cognitivos e a legitimação necessária para o exercício da profissão (DIMAGGIO; POWELL, 1983).

As pressões normativas estão atreladas às relações coesas, que levam as organizações a observarem outras para compreender as práticas eficazes e aceitáveis no sistema social onde estão inseridas, seguindo uma coerência de adequação. Nesse caso, as inovações tornam-se institucionalizadas devido ao elevado número de organizações que aderem a tais inovações. $\mathrm{O}$ mimético, por sua vez, tende a ocorrer em meio a incertezas; nesse caso, quando as inovações não são bem compreendidas, e os benefícios por sua adoção ainda são obscuros (DIMAGGIO; POWELL 1983).

Os isomorfismos coercitivo, normativo e mimético são compreendidos como resultado de ações legalmente sancionadas, moralmente autorizadas ou culturalmente amparadas, respectivamente. Entretanto, as estruturas culturais consistem em alicerces institucionais mais profundos por fornecer base para as normas e regras. Apesar disso, estudiosos têm detido a atenção em elementos reguladores, os quais, embora mais visíveis, tendem a ser mais frágeis e superficiais por serem mais rápidos que os culturais e normativos, originando muitas vezes manipulação em vez de conformidade (SCOTT, 2008).

Quanto à concorrência ou competitividade, Dimaggio e Powell (1983) sugerem que a visão do isomorfismo competitivo seria adequado numa realidade de competição livre e aberta, o que não ocorre nas organizações modernas, necessitando, portanto, do isomorfismo institucional, como fator complementar fundamental para verificação das pressões sofridas pelas entidades.

\subsection{Governança Corporativa em Fundos de Pensão}

A governança corporativa também tem sido examinada por pesquisadores no âmbito dos fundos de pensão em contextos e localidades distintos. Vasquez (2008) averiguou a qualidade da acessibilidade dos sites dos maiores fundos de pensão brasileiros, no que se refere à aderência às boas práticas de governança corporativa e à transparência informacional. $\mathrm{O}$ autor identificou que todos os sites da amostra necessitam de melhorias na acessibilidade e na divulgação online dos documentos que contêm informações vitais das Entidades Fechadas

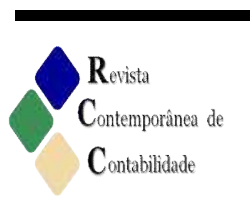


de Previdência Complementar (EFPC). Também há necessidade de ampliar sua disponibilização e inclusão de documentos não exibidos, principalmente o Manual de Governança Corporativa e o Manual de Ética, para completa aderência à Resolução CGPC n. $13 / 2004$.

Silva (2009) procurou detectar o comportamento das 10 maiores EFPCs de patrocínio público e das duas maiores EFPCs de Santa Catarina quanto ao cumprimento da legislação sobre governança corporativa. $\mathrm{O}$ autor constatou uma conformidade legal ampla, porém não completa por parte desses fundos, e mediana aderência ao código das melhores práticas, representando baixo nível de governança concernente ao que não está proposto na legislação, mostrando-se muito aquém do que se recomenda para a governança corporativa.

Ammann e Zingg (2010) investigaram a relação de governança dos fundos de pensões e desempenho dos investimentos, encontraram uma relação positiva entre governança de fundos de pensões e desempenho dos investimentos. Dentre as variáveis de governança que se destacaram pela influência significativa sobre o desempenho foi o tamanho do fundo como um fator de limitação à governança. Em geral, os fundos de pensão não apresentaram problemas de governança considerados graves, entretanto alguns, principalmente de pequeno e médio portes, apresentaram debilidades na transparência das metas de financiamento.

Lopes et al. (2010), averiguando a divulgação de informações das práticas de governança corporativa nos websites das EFPCs, depararam-se com a ausência de clareza quanto à evidenciação das práticas de governança corporativa para com os participantes e assistidos nas páginas eletrônicas, as quais funcionam como ambiente informacional sobre a gestão dos recursos dos planos.

Souto e Musalem (2012) forneceram um levantamento sobre governança, transparência, ativos e investimentos concernentes a 83 Fundos Nacionais Públicos de Pensões (NPPFs) localizados em 68 países. Identificaram uma grande dispersão na performance da governança e transparência dos fundos da amostra, e a necessidade de os governos considerarem reformas nas estruturas de governança dos NPPFs.

Kowalewski (2012) analisou a relação entre governança e desempenho dos fundos de pensões da Polônia. Teve como evidência a fragilidade dos mecanismos de governanças interna e externa em planos de previdência, o que pode ser explicado pelo conflito potencial entre os beneficiários de pensões e o(s) proprietário(s) do fundo, dependendo de quem assume o risco de investimento no plano. Concluiu ainda que mais foco deve ser dado à governança dos fundos de pensão, pois pode determinar o seu desempenho.

Jackowicz e Kowalewski (2012) buscaram fornecer uma nova visão sobre o impacto da estrutura de supervisão do conselho como um mecanismo de governança interna no desempenho do fundo de pensões da Polônia. Concluíram que o presidente, como um insider motivado, desempenha um papel importante na determinação do desempenho do fundo, e os outsiders também podem impactar positivamente o desempenho do fundo, entretanto com menor ímpeto. Obtiveram ainda como resultado que tanto a composição do conselho fisscal, bem como a motivação e o conhecimento de seus membros são importantes na explicação do desempenho dos fundos de pensão.

Duarte (2011) verificou como as práticas de governança adotadas pelas companhias são interpretadas pelos gestores de fundos de pensão e previdência do Brasil, do Chile e do México, e se essas práticas influenciam a tomada de decisão de investimento. A autora detectou que os administradores utilizam critérios de governança corporativa em suas análises de investimento.

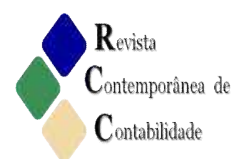


Cada uma das pesquisas citadas apresenta suas peculiaridades, algumas analisam a divulgação das práticas de governança ou outros mecanismos por parte dos fundos de pensão (VASQUEZ, 2008; LOPES et al., 2010; JACKOWICZ; KOWALEWSKI, 2012), e outras consideram a governança como um todo, por meio do estabelecimento de parâmetros que definem sua composição (SILVA, 2009; SOUTO; MUSALEM, 2012). Todavia, em todos esses trabalhos, são consideradas a importância da governança e a necessidade de essas entidades atentarem mais para suas práticas. Estudos ainda verificaram uma relação dessa governança com o desempenho dos fundos (AMMANN; ZINGG, 2008; KOWALEWSKI, 2012).

\subsection{Teoria Institucional e Governança Corporativa e Divulgação em Fundos de Pensão}

As assertivas da Teoria Institucional podem ser utilizadas por organizações de qualquer natureza, inclusive fundos de pensão, com o intuito de averiguar a adoção e divulgação de práticas de governança corporativa, objeto do presente estudo.

Vieira e Costa (2008) comentam que o isomorfismo coercitivo pode ser observado onde a governança corporativa é predominantemente fruto de regulação; o mimético, por sua vez, tende a atingir organizações com baixa regulação, que imitam concorrentes ou mesmo empresas de outros ramos; o normativo compreende principalmente entidades que sofrem pressão das profissões.

Said, Sulaiman e Ahmad (2013) investigaram a importância da informação ambiental nas decisões dos gestores de fundos e descobriram que esses profissionais a consideram importante, entretanto acreditam que a divulgação de informações ambientais deve ser obrigatória, pois reconhecem os requisitos legais como razão para incorporação dessas informações em suas decisões, reconhecendo a força do isomorfismo coercitivo.

Holder-Webb e Cohen (2012) examinaram os códigos de ética de empresas norteamericanas, deparando-se com conteúdos e linguagem convergentes entre as organizações e informações vagas e concluíram que os padrões éticos adotados nos códigos foram apenas uma resposta à regulamentação, ocasionando deficiências no conteúdo. Observa-se, assim, a tendência do isomorfismo coercitivo por conta das imposições no cumprimento de padrões éticos mais elevados, gerando falhas.

Essa pressão reconhecida no isomorfismo coercitivo também é referida por Woods e Urwin (2010), que observaram uma estrutura de governança destinada a suprir os fundos de pensão anglo-americanos com orientações práticas para a implementação de investimento sustentável e perceberam que a regulamentação também pode atuar como um facilitador de comportamento construtivo.

Em suma, o isomorfismo coercitivo destaca-se nos casos práticos identificados por estar atrelado a regulamentações ou pela expectativa de que venha a existir, deixando a impressão de que as semelhanças nas ações organizacionais são oriundas ou dependem principalmente de imposições regulamentadas.

Segundo Haunschild e Miner (1997), há três formas distintas de imitação no caso do isomorfismo mimético: com base na frequência, caracterizada pela adoção das práticas mais comuns; baseada em características como tamanho, prestígio e localização; e fundamentada em resultados, ou seja, práticas que geram provável impacto positivo. Haunschild e Miner (1997) ainda enfatizam que outra forma de imitação interorganizacional é aquela baseada em

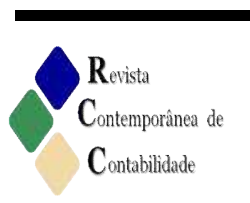


características. Esse caso abrange mais possibilidades, por exemplo, no caso dos fundos de pensão, como o patrocínio predominante, ou mesmo a própria idade e o tamanho.

Assim, entende-se que a Teoria Institucional também pode ser aplicada no âmbito da explanação da adoção e divulgação de práticas de governança. Os motivos que levam ao isomorfismo podem se alterar de acordo com a organização, como, por exemplo, pela busca por vantagem competitiva e legitimidade social. Pode haver casos em que a falta de adesão a tais ações afete negativamente a legitimidade social dos associados. Além disso, a qualidade ou eficácia das ações realizadas podem ser superficiais quando o propósito for apenas obter legitimidade ou podem ser eficazes, mesmo que não seja intencional. Vale ressaltar a possibilidade de o ambiente institucional intervir na dinâmica isomórfica (SUDARSANAM; BROADHURST, 2012).

Miller, Breton-Miller e Lester (2012) proferem sobre o destaque da legitimidade nas pesquisas referente ao ambiente competitivo, ressaltando, entretanto, a negligência no estudo dessa abordagem no contexto da governança. Argumentam que a legitimidade deve ser considerada atentando-se para os agentes organizacionais, principalmente aqueles que têm motivos para buscá-la. Afirmam, portanto, que as condições de governança possuem influência sobre a tendência por parte da empresa em solicitar a legitimidade como um comportamento estratégico.

Sievanen, Rita e Scholtens (2013) observaram isomorfismo mimético entre fundos de pensão europeus no tocante a características como tamanho, origem do sistema legal e estrutura de propriedade, quando investigaram os fatores determinantes desses fundos aos escolherem investimentos socialmente responsáveis. Foi usada regressão logística multinomial e, no tocante à característica tamanho dos fundos, foi estabelecida uma relação curvilinear e observaram que especialmente os fundos menores e os maiores da amostra tendiam a se engajar com investimentos responsáveis. Constaram que os investidores institucionais buscam mais transparência acerca de indicadores sociais, ambientais e de governança como estratégia de investimento a longo prazo.

No Brasil, a governança dos fundos de pensão está atrelada à gestão das Entidades Fechadas de Previdência Complementar (EFPC), que contempla a prestação de contas dos dirigentes e a conformidade legal dos atos praticados (que representam pressões coercitivas discutidas na Teoria Institucional), os quais são supervisionados pela PREVIC, que transformou as boas práticas de governança em princípios e recomendações objetivas (que representam pressões normativas), tendo em vista harmonizar os interesses dos participantes, patrocinadores e dirigentes dos fundos de pensão (que representam pressões culturalcognitivas).

Vale ressaltar que, na conjuntura dos fundos de pensão, a transparência vem conquistando espaço. A atenção dos fundos de pensão tem sido deslocada da simples prestação de contas e da mera formalização das relações organizacionais de poder para a evidenciação das informações organizacionais na medida necessária para que se possa verificar no interesse de quem a entidade está sendo conduzida (JARDIM, 2013).

Paula e Lima (2014) investigaram as informações contábeis elaboradas e divulgadas pelos fundos de pensão brasileiros segundo o padrão próprio brasileiro (de caráter coercitivo) e a aderência à norma contábil internacional Accounting and Reporting by Retirement Benefit Plans - IAS 26 (cuja obediência é de caráter normativo). Os resultados mostraram que as demonstrações contábeis dos fundos da amostra desse estudo se encontram, em sua maior parte, aderentes ao disposto na IAS 26, embora sua adesão não seja obrigatória, revelando 
isomorfismo normativo, embora tenham sido observadas, contudo, algumas divergências de caráter formal nas estruturas das demonstrações e na mensuração a valor justo dos investimentos.

\section{Metodologia da Pesquisa}

A natureza desta pesquisa é de caráter quantitativo, a qual é centrada na mensuração dos fenômenos, abrangendo o levantamento e o exame dos dados numéricos e a utilização de testes estatísticos. O trabalho caracteriza-se como descritivo, pois identifica aspectos peculiares de determinada amostra, buscando descrever o comportamento da população (COLLIS; HUSSEY, 2005).

Tendo em vista o alcance dos objetivos propostos, utilizaram-se dados secundários por meio de consultas realizadas nos portais eletrônicos dos fundos de pensão brasileiros constituintes da amostra e procedeu-se à análise documental. Foram aplicadas técnicas de estatística descritiva e de estatística inferencial, com o intuito de analisar práticas de governança corporativa adotadas e divulgadas pelos fundos de pensão estudados e explicar a existência de postura isomórfica entre eles a luz da Teoria Institucional.

A população desta pesquisa compreende os fundos de pensão brasileiros existentes em 2013, divulgados no site do Ministério da Previdência Social (MPS), conforme consulta realizada no dia 14 de julho de 2013, totalizando 323 fundos (MPS, 2013). As principais informações para esta pesquisa foram extraídas dos Relatórios Anuais (RA) e dos Estatutos referentes ao exercício de 2012, bem como dos websites das entidades pesquisadas. Foram excluídos os que não dispunham de um website ou estavam indisponíveis, portanto foram consultados dados de 190 fundos para composição da amostra. Posteriormente, foram excluídos os que não disponibilizavam acesso irrestrito aos citados documentos na internet, mesmo que em página eletrônica que não fosse do próprio fundo, e os que não possuíam as informações de tamanho ou idade. Resultaram 140 fundos os quais representaram a amostra utilizada na estatística descritiva, correlação e os devidos testes de média.

As práticas de governança adotadas pelos fundos de pensão foram verificadas mediante um checklist elaborado com base nas recomendações de práticas de governança em contextos gerais e de recomendações e regulamentações específicas para os fundos de pensão. Para tanto, foram considerados a cartilha com Recomendações sobre Governança Corporativa, da CVM; o Código das Melhores Práticas, do IBGC; o Guia das Melhores Práticas de Governança para EFPC, do MPS; a Lei Complementar n. 109/2001; as Resoluções CGPC n. 05/2002, n. 13/2004, n. 23/2006; a Instrução Normativa SPC n. 14/2007 (ver Quadro 1).

\section{Quadro 1 - Práticas de governança por categoria}

\begin{tabular}{|c|c|}
\hline Relativas à(ao) & Práticas \\
\hline 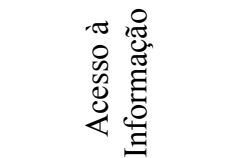 & $\begin{array}{l}\text { Disponibilização no website do Relatório Anual (RA), Código de conduta e/ou de } \\
\text { ética, Manual de governança, Estatuto, Regulamento dos planos, Regimento } \\
\text { interno, Ouvidoria ou outra forma de contato online. }\end{array}$ \\
\hline
\end{tabular}


Práticas de governança corporativa adotadas e divulgadas pelos fundos de pensão brasileiros.

\begin{tabular}{|c|c|}
\hline \multirow{3}{*}{ 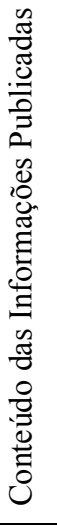 } & $\begin{array}{l}\text { Relatório Anual contendo: demonstrativo patrimonial, política de investimento, } \\
\text { premissas atuariais, demonstrativo de investimento, demonstrativo de despesa do } \\
\text { plano de benefícios, informações ambientais e sociais. }\end{array}$ \\
\hline & $\begin{array}{l}\text { Referência/divulgação no website/RA de Auditoria interna, Comitê de auditoria, } \\
\text { Monitoramento ou gestão de riscos, Demonstrativo de Resultados da Avaliação } \\
\text { Atuarial (DRAA), Parecer de auditores independentes, Parecer do conselho, } \\
\text { Informações sobre remuneração ou políticas de remuneração dos conselheiros e } \\
\text { gestores e sobre comitês consultivos de investimento ou de riscos. }\end{array}$ \\
\hline & $\begin{array}{l}\text { Estatuto contendo: Composição da diretoria e dos conselhos deliberativo e físcal, } \\
\text { Informações sobre as atividades/competências/atribuições dos conselhos, Duração } \\
\text { do mandato dos membros dos órgãos, Método de convocação de reuniões dos } \\
\text { conselhos, Autorização para qualquer conselheiro convocar reuniões necessárias } \\
\text { quando o encarregado não o fizer. }\end{array}$ \\
\hline \multirow{6}{*}{ 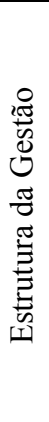 } & $\begin{array}{l}\text { Conselho Fiscal com no mínimo um terço das vagas compostas por participantes e } \\
\text { assistidos. }\end{array}$ \\
\hline & $\begin{array}{l}\text { Conselho Deliberativo com no mínimo um terço das vagas compostas por } \\
\text { participantes e assistidos. }\end{array}$ \\
\hline & O conselho deliberativo composto por 5 a 11 conselheiros. \\
\hline & O conselho fiscal composto por 3 a 5 conselheiros. \\
\hline & Prazo do mandato dos conselheiros entre 1 e 2 anos. \\
\hline & $\begin{array}{l}\text { Cargos de Diretor Executivo e Presidente do Conselho Deliberativo ocupados por } \\
\text { pessoas diferentes. }\end{array}$ \\
\hline
\end{tabular}

Fonte: Elaborado pelos autores.

Com base nas recomendações e regulamentações citadas, elaborou-se o checklist para a presente pesquisa, composto pelas categorias e subcategorias para análise da divulgação de práticas de governança dos fundos em estudo, conforme dispostas no Quadro 2. Consideramse como práticas obrigatórias aquelas dispostas na regulamentação vigente no momento da pesquisa; voluntárias, as recomendações propostas; e, parcialmente obrigatórias, aquelas cuja divulgação é exigida apenas para os participantes e/ou assistidos.

\begin{tabular}{|c|c|c|c|c|}
\hline \multirow{2}{*}{ Categorias } & \multirow{2}{*}{ Práticas } & \multirow{2}{*}{ Descrição das Práticas (Subcategorias) } & Documentos/ & \multirow{2}{*}{$\begin{array}{l}\text { Nota } \\
\text { Máxima }\end{array}$} \\
\hline & & & Palavras-Chave & \\
\hline \multirow{6}{*}{ 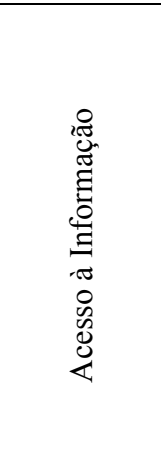 } & PPO 1 & $\begin{array}{l}\text { A entidade disponibiliza o Relatório } \\
\text { Anual (RA) em seu website? }\end{array}$ & Relatório Anual & \multirow{6}{*}{7} \\
\hline & PV 2 & $\begin{array}{l}\text { A entidade disponibiliza Código de } \\
\text { conduta e/ou de ética em seu website? }\end{array}$ & $\begin{array}{l}\text { Código de Conduta ou de } \\
\text { Ética. }\end{array}$ & \\
\hline & PV 3 & $\begin{array}{l}\text { A entidade disponibiliza manual de } \\
\text { governança em seu website? }\end{array}$ & Manual de Governança & \\
\hline & PPO 4 & $\begin{array}{l}\text { A entidade disponibiliza o Estatuto em } \\
\text { seu website? }\end{array}$ & Estatuto & \\
\hline & PPO 5 & $\begin{array}{l}\text { A entidade disponibiliza o Regulamento } \\
\text { dos planos em seu website? }\end{array}$ & Regulamento; Plano. & \\
\hline & PV 6 & $\begin{array}{l}\text { A entidade disponibiliza o Regimento } \\
\text { interno em seu website? }\end{array}$ & Regimento & \\
\hline
\end{tabular}

13 ISSN 2175-8069, UFSC, Florianopolis, v. 12, n. 27, p. 03-26, set./dez. 2015 


\begin{tabular}{|c|c|c|c|c|}
\hline & PV 7 & $\begin{array}{l}\text { A entidade disponibiliza ouvidoria ou } \\
\text { outra forma de contato eletrônico em seu } \\
\text { website? }\end{array}$ & $\begin{array}{l}\text { Ouvidoria; Fale conosco; } \\
\text { Contato; Email. }\end{array}$ & \\
\hline \multirow{22}{*}{ 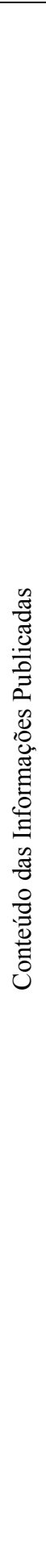 } & PPO 8 & $\begin{array}{l}\text { O RA contém o demonstrativo } \\
\text { patrimonial? }\end{array}$ & $\begin{array}{l}\text { Demonstrativo; Balanço } \\
\text { Patrimonial; Demonstração. }\end{array}$ & \multirow{22}{*}{23} \\
\hline & PPO 9 & $\begin{array}{l}\text { O RA contém as políticas de } \\
\text { investimentos? }\end{array}$ & Políticas; Investimento. & \\
\hline & PPO 10 & O RA contém as premissas atuariais? & $\begin{array}{l}\text { Atuariais; Premissas; } \\
\text { Hipóteses. }\end{array}$ & \\
\hline & PPO 11 & $\begin{array}{l}\text { O RA contém o demonstrativo de } \\
\text { investimento? }\end{array}$ & $\begin{array}{l}\text { Investimento; } \\
\text { Demonstrativo; Renda. }\end{array}$ & \\
\hline & PPO 12 & $\begin{array}{l}\text { O RA contém informações segregadas } \\
\text { sobre as despesas do plano de benefícios? }\end{array}$ & $\begin{array}{l}\text { Demonstrativo; } \\
\text { Demonstração; Plano; } \\
\text { Despesa; Resultado. }\end{array}$ & \\
\hline & PV 13 & O RA contém informações ambientais? & $\begin{array}{l}\text { Ambiental; Ambientais; } \\
\text { Ambiente. }\end{array}$ & \\
\hline & PV 14 & $\begin{array}{l}\text { O website/RA faz referência à existência } \\
\text { de auditoria interna? }\end{array}$ & $\begin{array}{l}\text { Auditoria; Auditor; interna; } \\
\text { interno. }\end{array}$ & \\
\hline & PV 15 & $\begin{array}{l}\text { O website/RA faz referência à existência } \\
\text { de comitê de auditoria? }\end{array}$ & Auditoria; Comitê. & \\
\hline & PV 16 & $\begin{array}{l}\text { O website/RA divulga processos sobre } \\
\text { monitoramento ou gestão de riscos? }\end{array}$ & Risco & \\
\hline & PPO 17 & $\begin{array}{l}\text { O website/RA divulga Demonstrativo de } \\
\text { Resultados da Avaliação Atuarial - } \\
\text { DRAA? }\end{array}$ & $\begin{array}{l}\text { Atuarial; Atuariais; } \\
\text { Demonstrativo; } \\
\text { Demonstração. }\end{array}$ & \\
\hline & PV 18 & $\begin{array}{l}\text { O website/RA divulga o parecer de } \\
\text { auditores independentes? }\end{array}$ & $\begin{array}{l}\text { Auditor; Independente; } \\
\text { Parecer. }\end{array}$ & \\
\hline & PV 19 & $\begin{array}{l}\text { O website/RA divulga o parecer do } \\
\text { conselho fiscal? }\end{array}$ & Parecer; Conselho. & \\
\hline & PV 20 & $\begin{array}{l}\text { O website/RA divulga informações sobre } \\
\text { remuneração (ou políticas de } \\
\text { remuneração) dos conselheiros? }\end{array}$ & $\begin{array}{l}\text { Politica; Remuneração; } \\
\text { Conselho; Conselheiro. }\end{array}$ & \\
\hline & PV 21 & $\begin{array}{l}\text { O website/RA divulga informações sobre } \\
\text { remuneração (ou políticas de } \\
\text { remuneração) dos gestores? }\end{array}$ & $\begin{array}{l}\text { Politica; Remuneração; } \\
\text { Gestor; Administrador; } \\
\text { Administração. }\end{array}$ & \\
\hline & PV 22 & $\begin{array}{l}\text { O website/RA disponibiliza informações } \\
\text { sobre comitês consultivos de } \\
\text { investimentos? }\end{array}$ & $\begin{array}{l}\text { Comitê; Assessoria; } \\
\text { Consultor; Consultoria; } \\
\text { Investimento. }\end{array}$ & \\
\hline & PV 23 & $\begin{array}{l}\text { O website/RA disponibiliza informações } \\
\text { sobre comitês consultivos de riscos? }\end{array}$ & $\begin{array}{l}\text { Risco; Comitê; Assessoria; } \\
\text { Consultor; Consultoria. }\end{array}$ & \\
\hline & PO 24 & $\begin{array}{l}\text { O Estatuto apresenta composição da } \\
\text { Diretoria? }\end{array}$ & Diretoria; Composta. & \\
\hline & PO 25 & $\begin{array}{l}\text { O Estatuto apresenta composição do } \\
\text { Conselho Deliberativo? }\end{array}$ & $\begin{array}{l}\text { Conselho Deliberativo; } \\
\text { Composto. }\end{array}$ & \\
\hline & PO 26 & $\begin{array}{l}\text { O Estatuto apresenta composição do } \\
\text { Conselho Fiscal? }\end{array}$ & $\begin{array}{l}\text { Conselho Fiscal; } \\
\text { Composto. }\end{array}$ & \\
\hline & PO 27 & $\begin{array}{l}\text { O Estatuto divulga informações sobre as } \\
\text { atividades/competências/atribuições dos } \\
\text { conselhos? }\end{array}$ & $\begin{array}{l}\text { Conselho Fiscal; } \\
\text { Deliberativo; Compete. }\end{array}$ & \\
\hline & PO 28 & $\begin{array}{l}\text { No Estatuto consta a duração do mandato } \\
\text { dos membros dos órgãos? }\end{array}$ & $\begin{array}{l}\text { Mandato; Conselheiro; } \\
\text { Conselho; Órgão; Ano. }\end{array}$ & \\
\hline & PV 29 & $\begin{array}{l}\text { O Estatuto contém o método de } \\
\text { convocação de reuniões dos conselhos? }\end{array}$ & Reuniões, Conselho. & \\
\hline
\end{tabular}

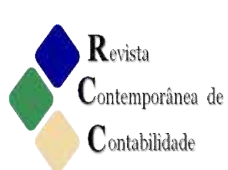


Práticas de governança corporativa adotadas e divulgadas pelos fundos de pensão brasileiros.

\begin{tabular}{|c|c|c|c|c|}
\hline & PV 30 & $\begin{array}{l}\text { No Estatuto consta autorização para } \\
\text { qualquer conselheiro convocar reuniões } \\
\text { necessárias, quando o encarregado não o } \\
\text { fizer? }\end{array}$ & $\begin{array}{l}\text { Convocar; Reunião; } \\
\text { Conselheiro; Conselho. }\end{array}$ & \\
\hline \multirow{6}{*}{ 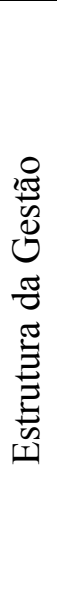 } & PO 31 & $\begin{array}{l}\text { Segundo o Estatuto, o Conselho Fiscal } \\
\text { deve ter no mínimo um terço das vagas } \\
\text { compostas por participantes e assistidos? }\end{array}$ & $\begin{array}{l}\text { Conselho Fiscal; Vaga; } \\
\text { Terço; Membro. }\end{array}$ & \multirow{6}{*}{6} \\
\hline & PO 32 & $\begin{array}{l}\text { Segundo o Estatuto, o Conselho } \\
\text { Deliberativo deve ter no mínimo um terço } \\
\text { das vagas compostas por participantes e } \\
\text { assistidos? }\end{array}$ & $\begin{array}{l}\text { Conselho Deliberativo; } \\
\text { vaga; terço; membro. }\end{array}$ & \\
\hline & PV 33 & $\begin{array}{l}\text { O conselho deliberativo possui entre } 5 \text { e } \\
11 \text { conselheiros? }\end{array}$ & $\begin{array}{l}\text { Conselho Deliberativo; } \\
\text { Conselheiro; Membro. }\end{array}$ & \\
\hline & PV 34 & $\begin{array}{l}\text { O conselho fiscal possui entre } 3 \text { e } 5 \\
\text { conselheiros? }\end{array}$ & $\begin{array}{l}\text { Conselho Deliberativo; } \\
\text { Conselheiro; Membro. }\end{array}$ & \\
\hline & PV 35 & $\begin{array}{l}\text { O prazo do mandato dos conselheiros } \\
\text { entre } 1 \text { e } 2 \text { anos? }\end{array}$ & $\begin{array}{l}\text { Mandato; Conselheiro; } \\
\text { Conselho; Órgão; Ano. }\end{array}$ & \\
\hline & PV 36 & $\begin{array}{l}\text { Os Cargos de Diretor Executivo e } \\
\text { Presidente do Conselho Deliberativo são } \\
\text { ocupados por pessoas diferentes? }\end{array}$ & $\begin{array}{l}\text { Conselho, Conselheiro, } \\
\text { Presidente, Diretor. }\end{array}$ & \\
\hline
\end{tabular}

Fonte: Elaborado pelos autores.

Legenda: $\mathrm{PV}=$ Prática Voluntária; $\mathrm{PO}=$ Prática Obrigatória; $\mathrm{PPO}=$ Prática Parcialmente Obrigatória.

Para cada subcategoria (Quadro 2) criou-se uma variável dummy, implicando pontuação 0 (zero), quando não cumprido o requisito da subcategoria, ou pontuação 1 (um), no cumprimento do requisito, obtendo-se uma nota para cada fundo de pensão, que pode variar de 0 (zero) a 36. Essa nota corresponde à pontuação obtida com as práticas de governança divulgadas pelas entidades. Dessa forma, cada categoria, Acesso à Informação, Conteúdo das Informações Publicadas e Estrutura de Gestão, recebe uma nota entre 0 (zero) e 7 (sete), 0 (zero) e 23, e 0 (zero) e 6, respectivamente, de acordo com o somatório da pontuação das subcategorias.

As técnicas estatísticas propostas nesta pesquisa foram aplicadas com recurso do Statistical Package for the Social Sciences (SPSS) 21.0. Consideraram-se as práticas de governança classificadas em voluntária, obrigatória ou parcialmente obrigatória, as quais equivalem ao total de 20, sete e nove práticas, respectivamente. Foi determinado e analisado por estatística descritiva o percentual de adoção e divulgação de cada prática. Os níveis de adoção e divulgação de práticas, no geral e por tipo, foram posteriormente analisados em relação às variáveis Idade, Tamanho (em termos de Ativo e Número de Participantes) e Patrocínio Predominante (Público, Privado e Institucional).

No caso do isomorfismo coercitivo, identificado por meio das Práticas Obrigatórias, e do normativo, estudado com base nas Práticas Voluntárias e Parcialmente Obrigatórias, a avaliação foi feita por meio de estatística descritiva.

Para apreender o isomorfismo mimético, utilizou-se a correlação de Spearman entre as práticas de governança corporativa e as variáveis: Idade e Tamanho (Ativo e Número de Participantes). Empregou-se também o teste t de amostras independentes para comparar as médias das seguintes variáveis: Práticas Voluntárias (PV), Práticas Obrigatórias (PO), Práticas Parcialmente Obrigatórias (PPO) e o Nível Total de adoção e divulgação das práticas de Governança Corporativa (NTGC), tendo como variável de agrupamento o Patrocínio dos fundos (Públicos e Não Públicos, estes últimos incorporando o Privado e o Instituidor).

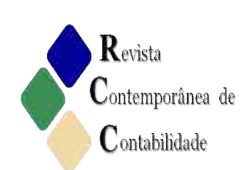




\section{Análise e Discussão}

$\mathrm{Na}$ Tabela 1, descrevem-se os resultados obtidos nas subcategorias de governança, considerando a quantidade $(\mathrm{N})$ de fundos da amostra, que corresponde a 140 entidades.

Tabela 1 - Percentual de adoção e divulgação de cada prática pelos fundos estudados

\begin{tabular}{|c|c|c|}
\hline \multicolumn{2}{|r|}{ Subcategorias } & $\mathrm{N}=140$ \\
\hline PPO 1 & A entidade disponibiliza o Relatório Anual (RA) em seu website? & $99,30 \%$ \\
\hline PV 2 & A entidade disponibiliza Código de conduta e/ou de ética em seu website? & $64,30 \%$ \\
\hline PV 3 & A entidade disponibiliza manual de governança em seu website? & $34,30 \%$ \\
\hline PPO 4 & A entidade disponibiliza o Estatuto em seu website? & $98,60 \%$ \\
\hline PPO 5 & A entidade disponibiliza o Regulamento dos planos em seu website? & $97,10 \%$ \\
\hline PV 6 & A entidade disponibiliza o Regimento interno em seu website? & $30,70 \%$ \\
\hline PV 7 & A entidade disponibiliza ouvidoria ou outro contato eletrônico em seu website? & $94,30 \%$ \\
\hline PPO 8 & O RA contém o demonstrativo patrimonial? & $95,00 \%$ \\
\hline PPO 9 & O RA contém as políticas de investimentos? & $97,90 \%$ \\
\hline PPO 10 & O RA contém as premissas atuariais? & $91,40 \%$ \\
\hline PPO 11 & O RA contém o demonstrativo de investimento? & $91,40 \%$ \\
\hline PPO 12 & O RA contém informações segregadas sobre as despesas do plano de benefícios & $94,30 \%$ \\
\hline PV 13 & O website/RA contém informações ambientais? & $49,30 \%$ \\
\hline PV 14 & O website/RA faz referência à existência de auditoria interna? & $7,90 \%$ \\
\hline PV 15 & O website/RA faz referência à existência de comitê de auditoria? & $2,90 \%$ \\
\hline PV 16 & O website/RA faz referência à existência de controle ou gestão de riscos? & $88,60 \%$ \\
\hline PPO 17 & $\begin{array}{l}\text { O website/RA divulga Demonstrativo de Resultados da Avaliação Atuarial - } \\
\text { DRAA? }\end{array}$ & $76,40 \%$ \\
\hline PV 18 & O website/RA divulga o parecer de auditores independentes? & $93,60 \%$ \\
\hline PV 19 & O website/RA divulga o parecer do conselho fiscal? & $87,10 \%$ \\
\hline PV 20 & $\begin{array}{l}\text { O website/RA divulga informações sobre remuneração (ou políticas de } \\
\text { remuneração) dos conselheiros? }\end{array}$ & $70,70 \%$ \\
\hline PV 21 & $\begin{array}{l}\text { O website/RA divulga informações sobre remuneração (ou políticas de } \\
\text { remuneração) dos gestores? }\end{array}$ & $59,30 \%$ \\
\hline PV 22 & $\begin{array}{l}\text { O website/RA disponibiliza informações sobre comitês consultivos de } \\
\text { investimentos? }\end{array}$ & $59,30 \%$ \\
\hline PV 23 & O website/RA disponibiliza informações sobre comitês consultivos de riscos? & $13,60 \%$ \\
\hline PO 24 & O Estatuto apresenta composição da Diretoria? & $100,00 \%$ \\
\hline PO 25 & O Estatuto apresenta composição do Conselho Deliberativo? & $100,00 \%$ \\
\hline PO 26 & O Estatuto apresenta composição do Conselho Fiscal? & $99,30 \%$ \\
\hline PO 27 & $\begin{array}{l}\text { O Estatuto divulga informações sobre as atividades/competências/atribuições dos } \\
\text { conselhos? }\end{array}$ & $100,00 \%$ \\
\hline PO 28 & No Estatuto consta a duração do mandato dos membros dos órgãos? & $97,90 \%$ \\
\hline PV 29 & O Estatuto contém o método de convocação de reuniões dos conselhos? & $79,30 \%$ \\
\hline PV 30 & $\begin{array}{l}\text { No Estatuto consta autorização para qualquer conselheiro convocar reuniões } \\
\text { necessárias, quando o encarregado não o fizer? }\end{array}$ & $15,70 \%$ \\
\hline PO 31 & $\begin{array}{l}\text { Segundo o Estatuto, o Conselho Fiscal deve ter no mínimo um terço das vagas } \\
\text { compostas por participantes e assistidos? }\end{array}$ & $93,60 \%$ \\
\hline
\end{tabular}

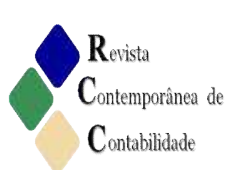


Práticas de governança corporativa adotadas e divulgadas pelos fundos de pensão brasileiros.

\begin{tabular}{l|l|c}
\hline PO 32 & $\begin{array}{l}\text { Segundo o Estatuto, o Conselho Deliberativo deve ter no mínimo um terço das } \\
\text { vagas compostas por participantes e assistidos? }\end{array}$ & $95,70 \%$ \\
\hline PV 33 & O conselho deliberativo possui entre 5 e 11 conselheiros? & $72,10 \%$ \\
\hline PV 34 & O conselho fiscal possui entre 3 e 5 conselheiros? & $91,40 \%$ \\
\hline PV 35 & O prazo do mandato dos conselheiros entre 1 e 2 anos? & $9,30 \%$ \\
\hline PV 36 & $\begin{array}{l}\text { Os Cargos de Diretor Executivo e Presidente do Conselho Deliberativo são } \\
\text { ocupados por pessoas diferentes? }\end{array}$ & $95,70 \%$ \\
\hline
\end{tabular}

Fonte: Dados da pesquisa.

Legenda: $\mathrm{PV}=$ Prática Voluntária; $\mathrm{PO}=$ Prática Obrigatória; $\mathrm{PPO}=$ Prática Parcialmente Obrigatória.

Os resultados da Tabela 1 indicam que as práticas menos divulgadas pelos fundos se referem à divulgação de existência de comitês de auditoria no website (PV 15), com apenas $2,9 \%$, e de auditoria interna (PV 14) com 7,9\%; ao prazo do mandato dos conselheiros (PV 35) com 9,3\%; à ausência de informações sobre comitês de riscos (PV 23) com apenas 13,6\% que prestam essa informação. Outra prática pouco divulgada é a autorização no Estatuto para que qualquer conselheiro possa convocar reuniões necessárias, quando o encarregado não o fizer (PV 30), com apenas 15,70\% que a divulgam. Vale ressaltar que essas quatro práticas com menor percentual de respostas positivas são voluntárias.

Em contrapartida, diversas práticas foram divulgadas por $100 \%$ dos fundos, como, por exemplo, a exposição no Estatuto da composição da Diretoria (PO 24) e do Conselho Deliberativo (PO 25), bem como as atribuições dos conselhos (PO 27).

Também se classifica com elevado percentual $(99,3 \%)$ a prática de disponibilizar o Relatório Anual no website (PPO 1), ou seja, apenas uma entidade da amostra não cumpriu esse requisito, e foi obtido na internet, mas em outra página eletrônica que não é da entidade. A composição do Conselho Fiscal (PO 26) seguiu também com 99,3\%.

Dessa forma, a maioria das práticas obrigatórias, que coincidentemente são concernentes ao Estatuto, é adotada em sua totalidade por esses fundos. A divulgação do Relatório Anual, parcialmente obrigatória, foi adotada quase totalmente, entretanto vale ressaltar que muitos fundos que não dispunham de RA no website ou na internet não foram contemplados na amostra justamente pela impossibilidade de análise no documento necessária para este trabalho.

Verificou-se ainda o Nível Total de Adoção e Divulgação das Práticas de Governança Corporativa (NTGC) dos fundos da amostra que variou entre 20 e 32 pontos com NTGC médio de 26,46. Considerando-se que a pontuação máxima é de 36 pontos, nenhum fundo a atingiu, mas todos apresentaram pontuação superior a 50\% (18 pontos), e a pontuação média girou em torno de 75\% (27 pontos). Assim, observa-se a existência de lacunas na divulgação de práticas governança dos fundos de pensão.

Observou-se que as práticas obrigatórias foram cumpridas em quase sua totalidade pelos fundos de pensão da amostra, variando em aproximadamente 93\% e 100\% de práticas atendidas. Esse tipo de achado corrobora as assertivas que respaldam a Teoria Institucional acerca do isomorfismo coercitivo, ou seja, as organizações tendem a imitar umas às outras por força de pressões advindas de institutos legais que têm o poder de impor sansões quando do seu descumprimento.

A prática de menor pontuação foi a PO31, apontando a ausência de informação no Estatuto de que o Conselho Fiscal tem no mínimo um terço das vagas compostas por participantes e assistidos, conforme a LC 109/2001. 
A média de pontuação foi de $97,86 \%$. Nesse caso, contempla-se a presença do isomorfismo coercitivo, devido à tendência do cumprimento de todas as práticas obrigatórias que são regulamentadas, concordando com Dimaggio e Powell (1983), Carvalho, Vieira e Goulart (2005) e Holder-Webb e Cohen (2012). Isso mostra que as práticas impostas legalmente tendem a ser predominantemente cumpridas por todos os fundos, repercutindo no isomorfismo coercitivo.

Dessa forma, a imposição por força de instituto legal de outras práticas de governança poderia contribuir para elevação do nível de governança corporativa nos fundos de pensão, em consonância com Said, Sulaiman e Ahmad (2013), que consideram a força do isomorfismo coercitivo e ressaltam que os gestores reconhecem os requisitos legais como razão para incorporação de práticas de divulgação de informações em suas decisões. Woods e Urwin (2010) também perceberam que a regulamentação pode atuar como um facilitador de comportamento construtivo da estrutura de governança.

Entretanto, Holder-Webb e Cohen (2012) chamam a atenção para possíveis deficiências no conteúdo de informações divulgadas como simples resposta à regulamentação, mostrando a possibilidade de o isomorfismo coercitivo gerar falhas.

As práticas voluntárias possuem baixo percentual de adoção e divulgação pelas entidades estudadas, variando de $30 \%$ a $85 \%$, não refletindo claramente uma homogeneidade entre os fundos e, consequentemente, não se percebe o isomorfismo normativo nessas práticas.

A PV15, que se refere à menção de comitê de auditoria no RA, apresentou a menor pontuação, $2,9 \%$, ou seja, apenas quatro fundos divulgaram essa informação no Relatório Anual. E a PV36 mostrou maior pontuação, com 134 fundos que divulgaram que o Diretor Executivo e Presidente do Conselho Deliberativo são ocupados por pessoas diferentes. A PV36 é considerada prática salutar, presente em muitos códigos de boa governança corporativa, é muito positiva também para os fundos e sua divulgação pode contribuir para a sua legitimidade. Ressalte-se que a divulgação dessa prática é voluntária, no Brasil, para os fundos de pensão e que a adoção dessa prática em si e sua divulgação não é comum em muitas corporações no País, conforme os achados de Sonza e Kloeckner (2014).

Outra pontuação elevada foi a da PV7, que se refere à disponibilização de ouvidoria ou outro contato eletrônico no website da entidade. Essa prática é recomendada pelo IBGC (2009), que considera necessária a existência de meios de comunicação, nos quais interessados possam expressar opiniões, críticas, reclamações e denúncias, como ouvidorias.

Em geral, observou-se que o cumprimento das práticas voluntárias varia muito entre os fundos de pensão estudados. Esse resultado conduz a uma reflexão sobre a baixa pressão normativa (tratado na literatura estrangeira como low enforcement) que influencie tais entidades a disponibilizarem informações mais claras sobre essas práticas, que de fato representaria o isomorfismo normativo. Em outras palavras, é baixa a aplicação das normas que recomendam a adoção e divulgação de práticas importantes e legítimas pelo fato de seu descumprimento não implicar sansões.

Já as práticas parcialmente obrigatórias de governança apresentaram por parte dos fundos estudados uma adoção e divulgação média de 93\%. As parcialmente obrigatórias, como são obrigatórias em relação à divulgação para os participantes e assistidos, percebe-se a tendência de adoção e divulgação em alto nível, refletindo um pouco da influência legal e do isomorfismo coercitivo.

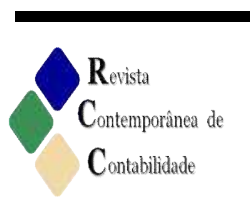


Percebeu-se que as Práticas Parcialmente Obrigatórias (PPO), cuja obrigatoriedade restringe-se à divulgação para os participantes e assistidos, apresentam-se, em sua maioria, acima de $90 \%$ de seu cumprimento por parte dos fundos, com exceção da prática PPO17, com aproximadamente $76 \%$. Mesmo assim, a variação entre a pontuação das práticas não é tão elevada como nas práticas voluntárias, refletindo maior homogeneidade entre os fundos quanto ao cumprimento dessas práticas.

Isso reflete que grande parte dos fundos disponibiliza, em seus websites, a todos os interessados o que é obrigatório disponibilizar apenas aos participantes e assistidos. Isso leva a pensar que esses fundos divulgam para todos as informações já produzidas e se eximem de divulgar outras informações simplesmente pelo fato de não querer fornecê-las, mas talvez por questões como custo de produção da informação, conforme achados de pesquisas de Claessens e Yurtoglu (2013) e Reis (2010).

A fim de identificar o isomorfismo mimético, procedeu-se à análise de correlação de Spearman entre as práticas de governança corporativa e as variáveis: Idade, Tamanho (Ativo e Número de Participantes), ilustrada na Tabela 2.

Tabela 2 - Correlações entre as práticas de governança e as variáveis idade, ativo e participantes

\begin{tabular}{|c|c|c|c|c|c|c|}
\hline & & & $\mathrm{NTGC}^{* * * * *}$ & $\mathrm{PV}^{* * *}$ & $\mathrm{PO}^{* * *}$ & $\mathrm{PPO}^{* * *}$ \\
\hline \multirow{9}{*}{$\begin{array}{l}\text { Coeficiente } \\
\text { de } \\
\text { Correlação } \\
\text { de } \\
\text { Spearman }\end{array}$} & \multirow{3}{*}{ IDADE } & Coeficiente & $0,180^{*}$ & $0,232^{* *}$ & 0,047 & $-0,069$ \\
\hline & & Valor $\mathrm{p}$ (bilateral) & 0,033 & 0,006 & 0,584 & 0,421 \\
\hline & & $\mathrm{N}$ & 140 & 140 & 140 & 140 \\
\hline & \multirow{3}{*}{ ATIVO } & Coeficiente & 0,144 & $0,230^{* *}$ & $-0,047$ & $-0,137$ \\
\hline & & Valor p (bilateral) & 0,090 & 0,006 & 0,578 & 0,107 \\
\hline & & $\mathrm{N}$ & 140 & 140 & 140 & 140 \\
\hline & \multirow{3}{*}{ PARTICIPANTES } & Coeficiente & 0,088 & 0,119 & 0,081 & $-0,114$ \\
\hline & & Valor p (bilateral) & 0,302 & 0,161 & 0,340 & 0,180 \\
\hline & & $\mathrm{N}$ & 140 & 140 & 140 & 140 \\
\hline
\end{tabular}

Legenda:

*. A correlação é significativa ao nível de 0,05 .

**. A correlação é significativa ao nível de 0,01 .

***. PV = Prática Voluntária; $\mathrm{PO}=$ Prática Obrigatória; $\mathrm{PPO}=$ Prática Parcialmente Obrigatória;

****. NTGC = Nível de adoção e divulgação das práticas de governança corporativa.

Fonte: Dados da pesquisa.

Avaliando as correlações (Tabela 2), nenhuma das variáveis (Idade, Ativo, Participantes) apresentou significância na relação às práticas obrigatórias e parcialmente obrigatórias, o que era de se esperar, tendo em vista que não houve muita variação entre os fundos nessas práticas.

Quanto às práticas voluntárias, apresentam correlação positiva e significativa ao nível de $1 \%$, com a Idade e o Ativo. Dessa forma, quanto maior a idade do fundo, maior a pontuação obtida no cumprimento das práticas voluntárias. Semelhantemente, quanto mais elevado o ativo total do fundo, maior a pontuação nas práticas voluntárias. Assim, observouse o isomorfismo mimético em relação à idade e ao tamanho do fundo, considerado pelo ativo, nas práticas voluntárias de governança corporativa. 
Esse resultado ampara a concepção de Haunschild e Miner (1997), que consideram o isomorfismo mimético também em imitação de práticas com base em características.

O Número de Participantes não mostrou correlação significativa para nenhum tipo de prática de governança. Nesse caso, amplitude no número de clientes, citada por Dimaggio e Powell, (1983), não incentivou o isomorfismo mimético.

Quanto ao NTGC, este apresentou correlação significativa com a Idade, ao nível de confiança de 5\%, e com o Ativo, ao nível de 10\%. Tal correlação foi provavelmente influenciada pelas práticas voluntárias, tendo em vista que as demais não se mostraram significativas. Esse tipo de achado corrobora as assertivas que respaldam a Teoria Institucional acerca do isomorfismo mimético, ou seja, as entidades com maior Idade e Ativo tendem a adotar e divulgar posturas semelhantes, divulgando as práticas mesmo sendo voluntárias, por perceberem que elas são consideradas legítimas, e sua adoção e divulgação representam os anseios dos participantes e assistidos, patrocinadores e dirigentes.

Verificaram-se as médias das práticas de governança por tipo de patrocínio e a significância da sua diferença estatística por meio do teste t de amostras independentes (Tabela 3), a fim de identificar a relação entre o Patrocínio e as práticas de governança.

Tabela 3 - Práticas de governança, por tipo de patrocínio

\begin{tabular}{|c|c|c|c|c|c|}
\hline & Patrocínio & $\mathrm{N}$ & Média & Desvio padrão & Valor $\mathrm{p}($ teste $\mathrm{t})$ \\
\hline \multirow{2}{*}{ NTGC**** } & Público & 51 & 0,759 & 0,082 & \multirow[t]{2}{*}{$0,005 * *$} \\
\hline & Não Público & 89 & 0,721 & 0,073 & \\
\hline \multirow{2}{*}{$\mathrm{PV}^{* * *}$} & Público & 51 & 0,644 & 0,118 & \multirow[t]{2}{*}{$0,001 * *$} \\
\hline & Não Público & 89 & 0,575 & 0,111 & \\
\hline \multirow{2}{*}{$\mathrm{PO}^{* * *}$} & Público & 51 & 0,992 & 0,034 & \multirow[t]{2}{*}{$0,029 *$} \\
\hline & Não Público & 89 & 0,971 & 0,075 & \\
\hline \multirow{2}{*}{ PPO*** } & Público & 51 & 0,928 & 0,125 & \multirow[t]{2}{*}{0,563} \\
\hline & Não Público & 89 & 0,939 & 0,092 & \\
\hline
\end{tabular}

Legenda:

*. A diferença é significativa ao nível de 0,05 .

**. A diferença é significativa ao nível de 0,01 .

***. PV = Prática Voluntária; $\mathrm{PO}=$ Prática Obrigatória; $\mathrm{PPO}=$ Prática Parcialmente Obrigatória;

****. NTGC = Nível de adoção e divulgação das práticas de governança corporativa.

Fonte: Dados da pesquisa.

Observa-se que no NTGC, bem como nas práticas voluntárias e obrigatórias, as médias $(75,92 \%, 64,41 \%, 99,15 \%)$ do grupo dos fundos de Patrocínio Público apresentaramse maiores do que no outro grupo. Apenas nas PPO, o grupo de Patrocínio Público mostrou menor média.

Por meio do teste t para amostras independentes, avaliou-se também se as diferenças entre os referidos grupos são significativas, observando as médias das pontuações dos fundos com Patrocínio Predominantemente Público e Não Público.

Tanto o nível de adoção e divulgação das práticas em geral (valor p de 0,005 ), quanto o das práticas voluntárias (valor $\mathrm{p}$ de 0,001 ) demonstraram diferenças significativas nos grupos ao nível de 1\%, constatando-se que os fundos com Patrocínio Público, em média, têm maiores pontuações que os de Patrocínio Não Público. As práticas obrigatórias apresentaram diferenças estatisticamente significativas a 5\%, com valor $\mathrm{p}$ de 0,029 . Apenas as parcialmente

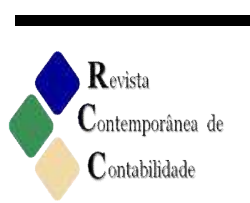


obrigatórias, em que o patrocínio público resultou em menor pontuação, não mostraram diferenças estatisticamente significativas entre os grupos.

Percebe-se, assim, a tendência de os fundos com patrocínio público apresentarem maior nível de governança, com destaque nas pontuações das práticas voluntárias. Isso corrobora o que foi argumentado na seção do referencial teórico, concernente à tendência de o tipo de patrocínio influenciar nas práticas, considerando a maior rigidez da Lei n. 108/2001, que não foi contemplada nas práticas coercitivas, tendo em vista que trata especificamente dos fundos vinculados a entidades públicas como patrocinadoras. Esse tipo de achado também corrobora as assertivas que respaldam a teoria acerca do isomorfismo mimético, ou seja, as práticas são voluntárias e ainda assim as entidades adotam postura semelhante no tocante à sua adoção e divulgação, no caso do estudo as entidades com Patrocínio Público mais essas práticas por serem consideradas legítimas e representarem os anseios de divulgação da sociedade.

Diante do exposto, apreendeu-se que as práticas de governança adotadas e divulgadas pelos fundos de pensão apresentam explicações à luz da Teoria Institucional, destacando-se o isomorfismo coercitivo nas práticas obrigatórias e o isomorfismo mimético nas práticas voluntárias em relação ao Patrocínio Predominantemente Público.

\section{Considerações Finais}

Averiguaram-se as práticas de acordo com a classificação: obrigatórias, voluntárias e parcialmente obrigatórias. As práticas adotadas e divulgadas por todos os fundos de pensão da amostra referem-se àquelas cuja divulgação é obrigatória, denotando a existência de isomorfismo coercitivo. Em contrapartida, as práticas com menor pontuação de adoção e divulgação são práticas voluntárias que apresentaram elevada variação quanto à divulgação e adoção, com percentuais baixos, médios e elevados.

Observou-se, neste estudo, a predominância do isomorfismo coercitivo na divulgação e adoção de práticas de governança corporativa, fruto de regulação, embora a regulamentação sobre governança corporativa dos fundos de pensão no Brasil ainda seja incipiente, ou seja, apenas sete das práticas de governança examinadas. A imposição de outras práticas de governança poderia contribuir para a elevação do nível de governança corporativa nos fundos de pensão, mas faz-se necessário atentar para que o cumprimento dessas imposições não seja superficial.

As práticas voluntárias apresentam elevada heterogeneidade, não se percebendo o isomorfismo normativo nessas práticas. A que se destaca, com maior pontuação, é a divulgação de que o Diretor Executivo e Presidente do Conselho Deliberativo são cargos ocupados por diferentes pessoas. Essa prática é recomendada no Brasil, considerando que a administração desempenhada pelos diretores é fiscalizada pelo conselho.

Outra prática voluntária com elevada pontuação foi a disponibilização de ouvidoria ou outro contato eletrônico no website da entidade. Essa prática também é recomendada no Brasil, considerando necessária a existência de meios de comunicação, nos quais os interessados possam expressar opiniões, críticas, reclamações e denúncias, como ouvidorias.

Em geral, observa-se que o cumprimento das práticas voluntárias varia muito entre os fundos de pensão estudados. Já as práticas obrigatórias foram divulgadas por todos os fundos. Traz-se, portanto, a reflexão sobre uma fragilidade na pressão social e legal capaz de

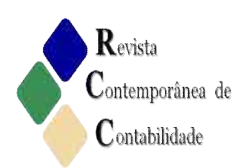


influenciar tais entidades a divulgarem informações sobre as práticas adotadas. Tal divulgação deveria ser mais clara e homogênea, o que de fato representaria o isomorfismo normativo ou coercitivo, respectivamente.

Quanto às práticas parcialmente obrigatórias, a média de divulgação foi elevada em quase todas, com exceção da prática concernente à divulgação do Demonstrativo de Resultados da Avaliação Atuarial, ainda com pontuação acima da média. Em geral, a variação entre a pontuação dessas práticas não é tão elevada como nas práticas voluntárias, representando maior homogeneidade entre os fundos quanto à divulgação dessas práticas.

Isso significa que grande parte dos fundos disponibiliza, em seus websites, a todos os interessados o que é obrigatório disponibilizar apenas aos participantes e assistidos. Observase, portanto, a ideia de que esses fundos divulgam a todos as informações já produzidas e se eximem de divulgar outras informações, corroborando achados de outros estudos para outros tipos de entidades.

Ao se correlacionarem as variáveis Idade e Tamanho com o nível de divulgação das práticas de governança, identificou-se o isomorfismo mimético nas práticas voluntárias quanto à Idade e ao Tamanho em termos de Ativo. Assim, quanto maior a idade do fundo ou quanto mais elevado o ativo total do fundo, maior a pontuação na divulgação das práticas voluntárias, também corroborando achados de outros estudos.

Analisou-se ainda o isomorfismo mimético nas práticas voluntárias em relação ao Patrocínio Predominante e constatou-se que os fundos com patrocínio público apresentaram maior nível de divulgação de práticas de governança, com destaque nas pontuações das práticas voluntárias. Isso pode ser reflexo da restrição da Lei n. 108/2001, que alcança apenas os fundos patrocinados por entidades públicas.

Concluiu-se, segundo a Teoria Institucional, que as práticas principalmente adotadas e divulgadas pelos fundos brasileiros decorrem de pressões coercitivas e culturais explicadas pelos isomorfismos coercitivo e mimético, ressaltando a importância das instituições reguladoras, bem como do papel da sociedade: participantes e assistidos, patrocinadores e dirigentes dos fundos de pensão (que enfatizam concepções compartilhadas consideradas legítimas e que representam seus anseios) para a efetividade da divulgação de informações sobre a governança corporativa desses fundos.

Reconhecendo as limitações da pesquisa, que abrange apenas as práticas de governança adotadas e divulgadas simultaneamente, propõe-se a elaboração de pesquisa com amostra pequena a fim de que também possam ser colhidos dados sobre práticas adotadas além das que são divulgadas. Essa redução da amostra e coleta de dados por meio de técnicas qualitativas, como entrevistas a gestores de fundos, permitiria o aprofundamento das análises, possibilitando analisar não somente as informações divulgadas nos sites das entidades, mas fazer inferências sobre o que é adotado e não é divulgado, principalmente à luz da Teoria Institucional. Por fim, sugere-se ainda estudos que sejam amparados por outras teorias com o intuito de atingir as peculiaridades dessas entidades.

\section{Referências}

AMARAL, H. F.; VILAÇA, C. S. I.; BARBOSA, C. F. M.; BRESSAN, V. G. F. Fundos de Pensão como Formadores de Poupança Interna: uma Alternativa para o Financiamento da

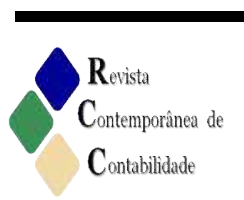


Atividade Econômica. RAC - Revista de Administração Contemporânea, v. 8, n. 2, p. 137-158, abr./jun. 2004.

AMMANN, M.; ZINGG, A. Performance and Governance of Swiss Pension Funds. Journal of Pension Economics and Finance, v. 9, n. 1, p. 95-128, 2010. Disponível em: $<$ https://www.alexandria.unisg.ch/publications/47632/L-en>. Acesso em: 29 out. 2013.

ASSOCIAÇÃO BRASILEIRA DAS ENTIDADES FECHADAS DE PREVIDÊNCIA Complementar - ABRAPP. Consolidado estatístico - junho de 2013. 2013. Disponível em: $<$ http://www.abrapp.org.br/SitePages/ConsolidadoEstatistico.aspx $>$. Acesso em: 4 out. 2013.

CARNEIRO, A. R. de A.; MAPURUNGA, P. V. R.; PONTE, V. M. R.; MORAIS, C. R. F. de. Governança corporativa em empresas brasileiras como determinante da evidenciação de benefícios a empregados. Revista Contemporânea de Contabilidade, UFSC, Florianópolis, v.10, n.19, p.157-178, jan./abr., 2013.

CARVALHO, C. A.; VIEIRA, M. M. F.; GOULART, S. A trajetória conservadora da teoria institucional. Revista de Administração Pública - RAP, Rio de Janeiro, n. 39, v. 4, p. 84974, jul./ago. 2005.

CLAESSENS, S.; YURTOGLU, B. B. Corporate governance in emerging markets: a survey. Emerging Markets Review, v. 15, p. 1-33, 2013.

COLLIS, J.; HUSSEY, R.. Pesquisa em Administração: um guia prático para alunos de graduação e pós-graduação. trad. Lucia Simonini. 2. ed. Porto Alegre: Bookman, 2005.

DIMAGGIO, P. J., POWELL, W. W. The iron cage revisited: institutional isomorphism and collective rationality on organizational fields. American Sociological Review, v. 48, p.147$160,1983$.

DUARTE, S. O. Governança corporativa, mercado de capitais e desenvolvimento econômico: estudo de casos dos fundos de pensão e previdência do Brasil, Chile e México. 2011. (Dissertação) Programa de Pós-Graduação em Integração Latino-americana (Prolam), Universidade de São Paulo (USP), São Paulo, 2011.

EVANS, J.; ORSZAG, M.; PIGGOTT, J. Pension fund governance: A global perspective on financial regulation. Cheltenham, UK: Edward Elgar, 2008.

HAUNSCHILD, P.; MINER, A. S. Modes of interorganizational imitation: The effects of outcome salience and uncertainty. Administrative Science Quartely, v. 42, n. 3, p. 472-500, 1997.

HEBB, T. The Economic Inefficiency of Secrecy: Pension Fund Investors' Corporate Transparency Concerns. Journal of Business Ethics, v. 63. p. 385-405, 2006. 
HOLDER-WEBB, L.; COHEN, J. The Cut and Paste Society: Isomorphism in Codes of Ethics. Journal of Business Ethics, v. 107, p. 485-509, 2012.

JACKOWICZ, K.; KOWALEWSKI, O. Crisis, internal governance mechanisms and pension fund performance: evidence from Poland. Emerging Markets Review, v. 13, p. 493-515, 2012.

JARDIM, M. C. A crise financeira de 2008: os discursos e as estratégias do governo e dos fundos de pensão. DADOS - Revista de Ciências Sociais, Rio de Janeiro, v. 56, n.4, p. 901941, 2013.

JIAO; Y.; YE, P. Public pension fund ownership and firm performance. Review of Quantitative Finance and Accounting, n. 40, p. 571-590, 2013.

KLAPPER, L. F.; LOVE, I. Corporate governance, investor protection, and performance in emerging markets. Journal of Corporate Finance, v. 10, p. 703-728, 2004.

KOWALEWSKI, O. Corporate governance and pension fund performance. Contemporary Economics, v. 6, n. 1, p. 14-44, 2012.

LOPES, J. E. G.; KATAOKA, S. S.; RIBEIRO FILHO; J. F.; PEDERNEIRAS, M. M. M. Um estudo sobre a divulgação das informações das práticas de governança corporativa nos sítios das entidades fechadas de previdência complementar. Revista Contemporânea de Contabilidade, Florianópolis, v.1, n. 13, p. 151-174, jan./jun., 2010.

MINISTÉRIO DE PREVIDÊNCIA SOCIAL (MPS). Previdência no Serviço Público. Disponível em: $<$ http://www.previdencia.gov.br/a-previdencia/previdencia-no-servicopublico/>. Acesso em: 17 out. 2013.

MINISTÉRIO DE PREVIDÊNCIA SOCIAL (MPS). Superintendência Nacional de Previdência Complementar (PREVIC). Divulgação das despesas administrativas do exercício de 2011 das entidades fechadas de previdência complementar. Série de estudos -

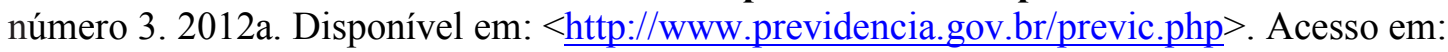
22 ago. 2013.

MINISTÉRIO DE PREVIDÊNCIA SOCIAL (MPS). Guia PREVIC: melhores práticas de governança para entidades fechadas de previdência complementar. 2012b. Disponível em: $<$ http://www.previdencia.gov.br/arquivos/office/1_121011-103451-807.pdf $>$. Acesso em: 22 jun. 2013.

OLIVEIRA, M. C.; ARAUJO JUNIOR, J. F.; OLIVEIRA, O. V.; PONTE, V. M. R. Disclosure Social de Empresas Brasileiras e Britânicas à luz da Teoria Institucional. Advances in Scientific and Applied Accounting, v. 5, p. 2-26, 2012.

MENDES, C. J. F.; FREIRE, F. S. A governança corporativa e manipulação de informação contábil: mensuração a valor justo nos bancos comerciais. Revista Contemporânea de 
Contabilidade, UFSC, Florianópolis, v. 11, n. 23, p. 53-76, maio/ago., 2014.

PAULA, R. A. de; LIMA, D. V. de. Aderência das demonstrações contábeis dos fundos de pensão do Brasil aos padrões contábeis internacionais: uma análise comparativa à luz da IAS 26. Revista Evidenciação Contábil \& Finanças, João Pessoa, v. 2, n. 2, p. 69-81, maio/ago. 2014.

PICCOLI, P. G. R.; SOUZA, A.; SILVA, W. V. da. As práticas de governança corporativa diminuem o gerenciamento de resultados? Evidências a partir da aversão na divulgação de prejuízos e de queda nos lucros. Revista Contemporânea de Contabilidade, UFSC, Florianópolis, v. 11, n. 22, p. 141-162, jan./abr., 2014.

PUNSUVO; K. E. K.; BARROS, L. A. B. C. O ativismo dos fundos de pensão e a qualidade da governança corporativa. Revista de Contabilidade e Finanças, USP, São Paulo, v. 18, n. 45, p. 63-72, set./dez. 2007.

REIS, A. A profissionalização dos órgãos estatutários das EFPCs. In: ROSA, S. (coord.). Governança Corporativa e os Fundos de Pensão. 1. ed. São Paulo, ABRAPP, 2010.

RODRIGUES NETO, A.; FREITAS, L. S. Análise do processo de adaptação estratégica de uma empresa produtora de cachaça à luz da teoria institucional e da visão baseada em recursos. REAd - Revista Eletrônica de Administração, Porto Alegre, ed. 71, n. 1, p. 211241, jan./abr. 2012.

ROSSONI, L.; MACHADO-DA-SILVA, C. L. Institucionalismo Organizacional e Práticas de Governança Corporativa. Revista de Administração Contemporânea - RAC, Curitiba, ed. especial, art. 7, p. 173-198, 2010.

ROSSONI, L.; MACHADO-DA-SILVA, C. L. Legitimidade, governança corporativa e desempenho: Análise das empresas da BM\&F Bovespa. RAE - Revista de Administração de Empresas, São Paulo, v. 53, n. 3, p. 272-289, maio/jun. 2013.

SAID, R. M.; SULAIMAN, M.; AHMAD, N. N. N. Do fund managers perceive environmental information useful? An empirical study from Malaysia. Journal of Cleaner Production, v. 52, p. 281-288, 2013.

SANTOS, S.O.; ANTUNES JUNIOR, J. A. V.; LEIS, R. P. Estratégia nos fundos de pensão do Brasil: contribuições para a construção de um modelo de análise. RAM - Revista de Administração Mackenzie, v. 9, n. 1, p. 37-63, 2008.

SCOTT, W. R. Approaching adulthood: the maturing of institutional theory. Theory and Society, v. 37, p. 427-442, 2008.

SILVA, R. V. Atendimento às regras, princípios e práticas de governança em entidades fechadas de previdência complementar. 2009. (Dissertação) Programa de Pós-Graduação 
em Contabilidade, Centro Sócio-Econômico, Universidade Federal de Santa Catarina, Florianópolis, 2009.

SONZA, I. B.; KLOECKNER, G. O. A governança corporativa influencia a eficiência das empresas brasileiras? Revista Contabilidade \& Finanças, USP, São Paulo, v. 25, n. 65, p. 145-160, maio/jun./jul./ago. 2014 .

SOUTO, P.; MUSALEM, A. R. Assessing the governance and transparency of national public pension funds. Review of European Studies, v. 4, n. 2, June 2012.

SUDARSANAM, S.; BROADHURST, T. Corporate governance convergence in Germany through shareholder activism: Impact of the Deutsche Boerse bid for London Stock Exchange. Journal of Management and Governance, v. 16, p. 235-268, 2012.

SIEVANEN, R.; RITA, H.; SCHOLTENS, B. The Drivers of Responsible Investment: The Case of European Pension Funds. Journal of Business and Ethics, v. 117, p. 137-151, 2013.

TOLBERT, P.; ZUCKER, L.The Institutionalization of Institutional Theory. In: CLEGG, S. R.; HARDY, C.; NORD. W. R. (Eds.). Handbook of organization studies. London: Sage Publishers, p. 175-190, 1996.

VASQUEZ, J. G. P. Acessibilidade dos websites e transparência informacional na perspectiva da governança corporativa dos fundos de pensão. 2008. (Dissertação) Universidade Federal de Santa Catarina, Florianópolis, 2008.

VIEIRA, C.; COSTA, N. R. Estratégia profissional e mimetismo empresarial: os planos de saúde odontológicos no Brasil. Ciência \& Saúde Coletiva, Rio de Janeiro, v. 13, n. 5, p. 1579-1588, 2008.

WOODS, C.; URWIN, R. Putting sustainable investing into practice: a governance framework for pension funds. Journal of Business Ethics. v. 92, p. 1-19, 2010. 